\title{
Modos de cuidar e educar a partir do Programa de Educação pelo Trabalho para a Saúde
}

Vitória Solange Coelho Ferreira(a)

Cristina Setenta Andrade ${ }^{(b)}$

Ana Maria Dourado Lavinsky Fontes ${ }^{(c)}$

Maria da Conceição Filgueiras de Araújo ${ }^{(\mathrm{d})}$

Soraya Dantas Santiago dos Anjos ${ }^{(e)}$

Ferreira VSC, Andrade CS, Fontes AMDV, Araújo MCF, Anjos SDS. Healthcare and education from the Education by Work for Health Program. Interface (Botucatu). 2015; 19 Supl 1:857-68.

Historically, the education of health professionals has focused on the construction of fragmented content that privilege biological determinism and disease as the object of consumption. The adoption of reorienting educational policies by educational institutions has stimulated new teaching and healthcare methods. This study aimed to analyze hinge mechanisms developed among managers, tutors, mentors, and fellows, featuring the devices that contribute to the reorientation to teaching and the development of new healthcare methods. This was an evaluative research work with a qualitative approach that used focus group, direct observation, and document analysis as data collection methods, followed by technical analysis of the data. The results show similarities between the services and education population, decreased fragmentation of content, strengthening of professional health education and teamwork, changes in the micro-policies at work, sharing of knowledge and practices, and the subjects' implications in their own works.

Keywords: Education by Work for Health Program (PET-Health). Continuous health education. Health education. Healthcare.
Historicamente, a formação dos profissionais de saúde tem privilegiado a construção de conteúdos fragmentados, o determinismo biológico e a doença como objeto de consumo. A adoção de políticas reorientadoras da formação, pelas instituições formadoras, tem estimulado novos modos de ensinar e cuidar. Este trabalho teve como objetivo analisar mecanismos de articulação desenvolvidos entre gestores, tutores, preceptores e bolsistas, caracterizando os dispositivos que contribuíram na reorientação da formação e produção de novos modos de cuidar. Optou-se pela pesquisa avaliativa de abordagem qualitativa. Foram utilizados: grupo focal, observação direta e análise documental, como instrumentos de coleta, e a análise de conteúdo como técnica de análise. Os resultados apontam: aproximações entre serviços/ensino/população, diminuição da fragmentação de conteúdos, fortalecimento da educação permanente em saúde e do trabalho em equipe, mudanças na micropolítica do trabalho, compartilhamento de saberes e práticas, implicação dos sujeitos com seu fazer.

Palavras-chave: Programa de Educação pelo Trabalho para a Saúde (PET-Saúde). Educação permanente em saúde. Formação em saúde. Cuidado em saúde. $(a, b, c, d, e)$ Colegiado de Enfermagem, Departamento de Ciências da Saúde, Universidade Estadual de Santa Cruz, Campus Soane de Nazaré. Rodovia Jorge Amado, Km 16, Salobrinho. Ilhéus, Ba, Brasil. 45662-900. vitsoll@gmail.com; cristina70@uol.com.br; anamarialavinsky@uol.com. br; confilgueiras@gmail.com; soraya.dsa@gmail.com 


\section{Introdução}

Historicamente, a formação superior dos profissionais de saúde tem privilegiado a construção de conteúdos fragmentados em diversas disciplinas; e organiza-se em torno de relações de poder que colocam o saber do professor especialista em posição de destaque no processo de ensino-aprendizagem ${ }^{1,2}$.

Nessa relação, os estudantes, sujeitos passivos do aprendizado, com pouca autonomia e capturados pelo modelo hegemônico de ensino, privilegiam o determinismo biológico e a doença como objeto de consumo.

Os processos formativos desses profissionais, cuja natureza é instrumentalizar as "novas gerações de pensadores"3 (p. 236), têm produzido comportamentos cristalizados e de resistência contra os avanços no Sistema Único de Saúde (SUS), na medida em que permanecem " [...] alheios à organização da gestão setorial e ao debate crítico sobre os sistemas de estruturação do cuidado, mostrando-se absolutamente impermeável ao controle social sobre o setor [...]"4 (p. 42).

Apesar dos avanços quanto à acessibilidade aos serviços e maior resolutividade dos problemas de saúde na atenção primária, fragilidades na gestão e no modo de operar o trabalho em saúde são, ainda, sentidos na formação. As vivências dos sujeitos, em suas práticas tradicionais, dificultavam a articulação de saberes e práticas interdisciplinares, horizontais e democráticas.

A criação da Secretaria de Gestão do Trabalho e da Educação na Saúde (SEGETES), em 2003, possibilita o Ministério da Saúde (MS) formular políticas orientadoras da formação, desenvolvimento, distribuição, regulação e gestão dos trabalhadores de saúde do Brasil. A adoção dessas políticas ordenadoras da formação - a exemplo, do Aprender SUS, Programa Nacional de Reorientação da Formação dos Profissionais de Saúde (Pró-Saúde) e o Programa de Educação pelo Trabalho para Saúde (PET-Saúde) - toma a integralidade, a intersetorialidade e a educação permanente em saúde (EPS) como idéia-síntese, e passa a influenciar os processos formativos com mudanças no modo de ensinar e de operar o cuidado dos futuros profissionais ${ }^{5-7}$.

No que pesem as mudanças ocorridas nos currículos dos cursos de saúde, a maioria das instituições formadoras continua a privilegiar modelos conservadores centrados no uso extensivo das tecnologias duras, em detrimento das tecnologias leves e leve-duras, que privilegiam as relações entre profiss ionais-usuários-alunos-professores ${ }^{3,4,8}$. Pouco se constrói a partir destes encontros, do olhar do outro, do sentimento do outro, do conhecimento e inquietações do outro.

Conforme Ceccim e Feuerweker

[...] As instituições formadoras têm perpetuado modelos essencialmente conservadores, centrados em aparelhos e sistemas orgânicos e tecnologias altamente especializadas, dependentes de procedimentos e equipamentos de apoio diagnóstico e terapêutico. ${ }^{4}$ (p. 42)

Essa modelagem aponta para a necessidade de um debate interdisciplinar entre biólogos, clínicos, sanitaristas e ambientalistas como dispositivo potente de ampliação do olhar do sujeito epistêmico para além dos fatos mais visíveis dos processos cuidadores e formadores, ampliando e qualificando as discussões sociopolíticas e o compromisso social de todos os envolvidos nesta construção, ${ }^{9,10}$.

Em relação à produção do cuidado, observa-se que, apesar do grande investimento por gestores e trabalhadores de saúde em programas educacionais, não vêm ocorrendo mudanças significativas nas práticas de cuidado, o que sugere que as práticas pedagógicas sejam direcionadas para a implicação dos sujeitos em um campo de subjetivação de novos modos de operar o cuidado em saúde. Tal perspectiva ultrapassa o âmbito da cognição para outros territórios, em que olhares e afetações atravessam os envolvidos no ato de cuidar ${ }^{11}$.

O PET-Saúde é desenvolvido por grupos de estudantes e preceptores (profissionais de saúde) com tutoria de um docente, organizados a partir de cursos de graduação das IES públicas e privadas sem fins lucrativo, orientadas pelo princípio da indissociabilidade entre o ensino, pesquisa e extensão. Tem por objetivo desenvolver atividades acadêmicas participativas e interdisciplinares, 
(f) Em Baremblitt ${ }^{13}$, dispositivo "é uma montagem ou artifício produtor de inovações que [...] atualiza virtualidades $[\ldots]^{\prime \prime}$ (p. 135). contribuindo para a elevação critica dos alunos e uma atuação profissional pautada na ética e pela cidadania.

Após três anos de experiências do PET-Saúde da Universidade Estadual de Santa Cruz (UESC), em Unidades de Saúde da Família (USF's), de dois municípios da região Sul do Estado da Bahia, tornou-se possível analisar os movimentos e fluxos gerados por esse Programa, e responder questões que se tornaram balizadoras deste estudo: De que forma se desenvolveram as experiências do PET-Saúde, nos municípios investigados? Quais os mecanismos de articulação desenvolvidos? Quais as contribuições para a formação e a produção do cuidado?

Assim, foram traçados os seguintes objetivos: analisar os mecanismos de articulação desenvolvidos entre gestores, tutores, preceptores e bolsistas; e caracterizar os dispositivos que contribuíram na reorientação da formação profissional e na produção de novos modos de cuidar.

\section{Trajetória metodológica}

Trata-se de uma pesquisa avaliativa de abordagem qualitativa, sobre as experiências desenvolvidas no PET-Saúde da UESC, em USFs de dois municípios localizados na Região Sul do Estado da Bahia. A base teórico-metodológica dessa investigação foi subsidiada pelas dimensões de análise da reorganização da atenção à saúde e processos formativos, destacando aspectos relacionados à gestão do trabalho, do cuidado e educação permanente em saúde na formação dos profissionais.

Utilizaram-se, para análise dessas experiências, as dimensões avaliativas proposta por Donabedien ${ }^{12}$ : a) estrutura: analisou-se a formação profissional e os projetos elaborados; b) processo: os dispositivos ${ }^{f}$ geradores de movimentos instituintes de mudança no processo de trabalho da equipe, em especial, dos preceptores, tutores e bolsistas, pela possibilidade de apreender inovações no modo de ensinar, de produzir um cuidado integral e de implementar projetos de pesquisa voltados para as necessidades locais; e c) resultado: o impacto/mudanças na produção do cuidado operado pelas equipes saúde da família (ESFs), na formação dos alunos bolsistas da UESC e no processo de trabalho da ESF e dos professores tutores da UESC.

O estudo teve como técnica de coleta de dados: o grupo focal (GF), observação direta e a análise documental. Foram realizados cinco GFs, constituídos de, no mínimo, cinco e, no máximo, nove participantes de cada segmento que atuavam no PET-Saúde: tutores (professores), preceptores (profissionais de saúde) e estudantes (bolsistas). Destes foram realizados: um GF com os tutores dos dois municípios; dois GFs com os preceptores, um para cada município, e dois GFs com os estudantes, sendo um em cada município.

Os critérios de seleção dos grupos e número de participantes seguiram a relação de tutor $\mathrm{x}$ preceptor $\mathrm{x}$ bolsista proposta pelo Ministério da Saúde (um tutor para cada dois preceptores e 12 alunos para cada preceptor).

Em relação à amostra, a diversidade da mesma e o processo de saturação dos discursos presentes nos atos de fala, no transcorrer das entrevistas, são importantes critérios de validação da investigação ${ }^{14}$.

A investigação foi aprovada pelo Comitê de Ética em Pesquisa (CEP) da UESC, e o termo de consentimento livre e esclarecido (TCLE) foi assinado pelos participantes após a sua leitura e esclarecimentos acerca de seu teor. 
A análise de dados articulou a tríade avaliativa de Donabedian, seus respectivos descritores e os objetivos da investigação, tendo como eixo balizador essa articulação e os três momentos de análise, sugeridos por Minayo ${ }^{14}$.

No primeiro momento, foi realizada leitura "flutuante" e a estruturação do mapa das "falas". Neste, foram colocados, na vertical, os grupos de falas, organizados na forma de "corpus de comunicações", e, na horizontal, os eixos temáticos classificados segundo as dimensões avaliativas e os objetivos da investigação, em que as falas contidas em cada corpus foram recortadas ${ }^{14}$ (p. 235). Para a constituição do corpus, as falas foram agrupadas de acordo os três grupos: tutores, preceptores e bolsistas.

No segundo momento, mediante uma análise descritiva do material empírico, foi realizada a leitura detalhada do mapa de entrevistas, seja verticalmente, objetivando especificar o tema presente em cada um dos corpus ou grupo de entrevistados, seja horizontalmente, iniciando uma comparação entre esses temas. Foram definidos, então, os temas mais relevantes e as categorias analíticas centrais (estrutura, processo e resultado).

Por fim, no terceiro momento, concluiu-se o processo de análise, por meio da etapa interpretativa, estabelecendo-se um confronto entre o discurso dos entrevistados e as reflexões teóricas em torno das categorias definidas acima.

\section{Resultados e discussões}

Apesar do distanciamento das gestões dos problemas enfrentados pelos profissionais de saúde no nível local, percebe-se que a presença da academia na unidade de saúde constitui elemento motivacional importante para as equipes de saúde, instigando a curiosidade científica e fomentando o debate sobre as diversas situações vivenciadas no cotidiano, em que os trabalhadores trocam experiências entre si e com os acadêmicos, preceptores e tutores.

\section{Dispositivos que contribuíram na reorientação da formação profissional e na produção de novos modos de cuidar}

As características peculiares do sistema de saúde municipal têm constituído um desafio tanto para a gestão quanto para a formação, na implementação de ações de promoção à saúde eficazes e oportunas e na busca de soluções criativas, que contribuam com a organização dos serviços e valorizem o trabalhador de saúde, os acadêmicos e, em especial, a comunidade usuária.

Nessa direção, torna-se importante a implementação de currículos sensíveis às necessidades do trabalho e às demandas localizadas, sendo necessário desenvolver espaços de diálogo para escuta das práticas curriculares em territórios de produção do cuidado, que integrem ensino-serviço-comunidade e discutam os processos formativos em saúde, estimulando o trabalho em equipe, em que saberes, fazeres, poderes e responsabilidades possam ser compartilhados ${ }^{15}$.

No processo de formação dos profissionais em saúde, a aproximação com os diversos cenários de práticas estrutura e mobiliza saberes e práticas que ajudam a integrar um corpo de conhecimentos pautados em habilidades na atenção à saúde e competências profissionais, desenvolvidos no decorrer da graduação, que irão refletir futuramente na qualidade dos serviços e do cuidado prestados ao indivíduo, a família e a comunidade.

A implantação do PET-Saúde tem possibilitado, em ato, a vivência de processos formativos voltados para necessidades do trabalho e demandas locorregionais, sendo considerado, pelos entrevistados, como um dispositivo que possibilita, ao aluno, vivenciar e construir, com as equipes, uma reflexão acerca das práticas de saúde e da construção de vínculos sem maiores campos de tensão.

Esse experimentar possibilitou, também: a ampliação e melhoria da relação institucional, estímulo ao diálogo, entre diferentes atores, sobre as necessidades e características definidoras do sistema de saúde, que contribuem para melhorar a formação do acadêmico, além de contribuir substancialmente para a reflexão das práticas pedagógicas dos docentes envolvidos. 
“O PET é uma importante troca de aprendizado com as equipes no fazer [...] é um dispositivo no meu processo de reflexão permanente [...] proporciona retomar a aproximação com as equipes e perceber que somos reciprocamente importantes [...] é uma motivação para todos." (T1)

(g) Potência para

Baremblitt' ${ }^{13}$, são " $[\ldots]$

capacidades virtuais

ou atuais de produzir,

inventar, transformar,

[...]." (p. 163). Tem

influência do pensamento

nietzscheano, sendo

considerada "a

vontade de durar, de

crescer, de vencer, de

estender e intensificar

a vida, um desafio à

transmutação dos valores

estabelecidos." 16 (p. 104).

(h) Em Deleuze e Guattari17,

"[...] o agenciamento

é o crescimento das

dimensões numa

multiplicidade que

muda necessariamente

de natureza à medida

que ela aumenta suas

conexões" (p. 17).

(i)Em Barremblitt'13 o

instituinte aparece

como uma atividade ou

força revolucionária,

transformadora e criativa,

que tende a mudar ou

alterar uma instituição.

São forças produtivas de

lógicas institucionais. $\mathrm{Na}$

instituição, representa

o momento da

particularidade

(i) Em Guatarri e Rolnik ${ }^{19}$,

micropolítica estaria

situada no cruzamento

entre diferentes modos

de apreensão de uma

problemática.
"Como estudante é mais fácil interagir com as equipes e estabelecer a discussão da linha do cuidado, de forma mais horizontal [...], daí estabelecemos melhor os vínculos com as equipes dos serviços." (E1)

Observa-se um componente espinoziano nessa afecção descrita como "motivação para todos". Percebe-se que existe potênciag nesse lugar que se revela como um agenciamento ${ }^{\mathrm{h}}$ na produção de novos acontecimentos, saberes e práticas.

Nesta perspectiva, a educação opera no mundo das relações de ensinoaprendizagem como dispositivo, em uma ação pedagógica que agencia processos de subjetivação, associados aos de cognição, pois, só assim, contribuiria na produção de sujeitos, entendidos como coletivos com capacidade de intervir na realidade com o objetivo de transformá-la ${ }^{11}$.

A articulação e o compartilhamento de saberes, práticas e responsabilidades entre as categorias profissionais possibilitaram o estabelecimento de processos dialógicos e a horizontalização das relações de poder impostas pela divisão social e técnica do trabalho, abrindo espaços para participação ativa nas ações desenvolvidas.

"A nutricionista foi fundamental na nossa integração. Ela, ao falar da conduta terapêutica, fortalecia o processo de enfermagem. [...] A nutricionista tinha uma bagagem grande na área da saúde coletiva." (A4)

Os diferentes níveis de implicação dos sujeitos envolvidos no processo de cuidar apontam a construção de diversas subjetividades na dependência dos processos cotidianos vivenciados ao longo da vida de cada um. Aqui, o sentido de implicação deve levar em conta os pertencimentos institucionais do pesquisador junto ao estabelecimento em estudo. Para $\operatorname{Lourau}^{18}$ (p. 56) "[...] se avaliará a implicação institucional do indivíduo (grupo, organização) como a soma de pertencimentos (subjetivos e objetivos) e referências na qual se inscreve".

Ademais, o protagonismo de sujeitos com capacidade de processos autoanalíticos e autogestionários diz respeito à apropriação de um saber acerca de si, de suas necessidades, demandas, problemas, limites e soluções, e baseiam-se em princípios humanitários e de solidariedade em um processo instituintei potencializador de um novo modo de produzir saúde e reorganizar os processos de trabalho ${ }^{11,13}$.

Dessa forma, a atenção direcionada à necessidade do indivíduo, nas ações do PET-Saúde, deve ser construída tendo como pressupostos a relação dialógica entre os sujeitos do cuidar, que proporciona o desenvolvimento de cada um, no qual as individualidades, as crenças, a linguagem, entre outras, devem ser respeitadas.

Mecanismos de articulação desenvolvidos entre a Equipe de Saúde de Família (ESF), tutores, preceptores, alunos e a comunidade [subtítulo]

$\mathrm{Na}$ prática do cotidiano de trabalho das equipes, deve-se ter, como exigência ético-política, um sistema de gestão de trabalho e de cuidado que ofereça oportunidades de transformação das práticas profissionais, tendo 
como dispositivo: a aprendizagem significativa, a reflexão crítica sobre o trabalho em saúde e a experimentação da alteridade com os usuários. Esses pressupostos permitem, na micropolíticaj das relações da gestão setorial e da estruturação do cuidado em saúde, que se incorporem, ao aprender e ao ensinar, modos diferenciados de ensinar e cuidar, mais próximos à realidade e ao perfil profissional exigido pelo SUS.

Nessa perspectiva, os mecanismos de articulação que serviram como analisadores deste processo foram: a EPS, as reuniões em equipe, as visitas domiciliares e a própria investigação, que serão apresentadas nos tópicos a seguir.

\section{Pesquisa como dispositivo de produção do cuidado e de conhecimento}

A realização da pesquisa produziu diversos afetos e bons encontros geradores, ora de paixões alegres, ora de tristes, ao possibilitar diferentes e complexas composições com a produção de conhecimento técnico, cientifico e do senso comum, ao ampliar o acesso às informações e permitir a análise e compreensão da realidade de saúde das comunidades, possibilitando a busca por soluções efetivas e inovadoras.

“Estudantes de medicina não tinham a mínima idéia de como fazer o levantamento de dados, foram fornecidos artigos científicos sobre o tema e eles passaram a entender o que era um dado epidemiológico. [...] o grande ganho foi aprender a produzir a partir dos dados levantados/coletados." (T2)

Os problemas identificados nas USFs passam a ser objeto de investigação e intervenção, articulado com a gestão municipal na busca de minimizar nós críticos a serem enfrentados na micropolítica do trabalho em saúde e na construção de linhas de cuidado. Os preceptores referem que o tutor é um facilitador do processo, ao orientar e estimular a produção do conhecimento a partir das necessidades dos serviços e demandas locais.

“[...] Exigiu aprimorar a sensibilidade para a escuta e a observação sistemática nesse espaço com todos do grupo e extrair elementos e conteúdos para orientar e produzir alguns trabalhos científicos, partindo [...] das necessidades do serviço como fonte de produção de conhecimento e pesquisa na universidade." (P5)

Um dos problemas identificados refere-se à fragilidade na condução da visita domiciliar, prática rotineira no cotidiano do trabalhador, por levar muito pouco em consideração a singularidade dos usuários no atendimento de suas necessidades. Os prontuários, também, eram pouco observados para análise das necessidades antes das visitas; e a pouca utilização das tecnologias leves não demandava uma escuta qualificada para a realização de projetos terapêuticos potentes.

A visita domiciliar tem como objetivo avaliar as necessidades e problemas dos usuários e familiares e o ambiente onde vivem, para a construção e acompanhamento de projetos terapêuticos singulares a partir do conhecimento da realidade dos usuários assistidos ${ }^{20}$. Investigações sobre a temática desencadearam a criação de protocolos e produção de trabalhos científicos:

"Iniciamos trabalhando com a visita domiciliar. Trabalhamos com Portarias vimos às diferenças no processo de trabalho. Os alunos dos últimos semestres fizeram o PPLS para fazer a territorialização, fizemos questionários. [...]. Foi feita com toda a equipe a visita domiciliar e a recepcionista pode perceber o trabalho de cada membro da equipe. Daí saiu 06 projetos. Então vimos à diferença do aluno que participa do PET e o outro que não." (T1)

Para a formação discente, o acúmulo de dados transformados em informações aliado à experiência vivenciada na prática da atenção primária à saúde, permitiu aproximações sucessivas com a realidade dos serviços, consolidação da teoria apreendida na revisão de literatura sobre SUS e a ampliação da visão crítica sobre elementos de entraves à sua consolidação. Foi observado que nem sempre as 
(k) Em Deleuze ${ }^{21}$, afecção é o estado de um corpo quando sofre ação de outro corpo: "[...] a mistura de um corpo com um outro corpo" (p. 36-7). condições do meio e as características dos atores sociais envolvidos permitiram que aquilo que está posto em forma de norma se transforme em ato concreto nas ações assistenciais.

\section{Educação Permanente em Saúde como dispositivo de reorientação da formação profissional no SUS e de produção de novos modos de cuidar}

A EPS possibilitou no PET-Saúde: a experimentação de novas abordagens nos processos de produção do cuidado em saúde, (re)significação do processo ensinoaprendizagem para os discentes, equipe de saúde da família, preceptores e tutores.

\footnotetext{
“No meu processo de formação, a experiência foi enriquecedora. A equipe esta sempre esperando que seja fortalecida e eu estava me fortalecendo também. Também a troca, na busca de conhecimento. [...] O clima é diferente, é porque todos estão querendo. Cheguei a me arrepiar!" (T4)
}

Nas USFs, o PET-Saúde conseguiu produzir bons encontros e "afecções"k nos espaços de produção do cuidado e da formação; e, nesse processo de ensinar, aprender a aprender, produtor de sentidos, significados e implicações, são construídas práticas pedagógicas problematizadoras e ações tecnológicas mais relacionais e humanizadas no ato do cuidar.

Esse processo de produção revela um espaço comum de trocas, intercessoras, que se produz nas relações entre "sujeitos" no espaço de suas interseções, que é produto que existe para os "dois" em ato que avança, paralisa, reflete e escuta o outro na busca de novos processos, de um em relação ao outro ${ }^{8}$.

“[...] Os grupos de aprendizagem tutorial possibilitaram não só a articulação, mas, sobretudo a convergência para as descobertas e preocupações, senso de cooperação mútua, estimulou a criatividade e a construção coletiva entre os alunos, [...], na busca em solucionar problemas identificados no serviço, de caráter interpessoal com a equipe, técnico profissional ou pedagógico e inserindo a comunidade nesse processo." (T5)

Os cenários de produção do cuidado, como cenários de produção pedagógica, re-significam a educação na saúde e colocam-na para além da relação ensinoaprendizagem, mas no âmbito dos processos de cognição e mudança na práxis social, com o sentido de criar grupos e sujeitos capazes de assumirem, para si, o protagonismo, como sujeitos sociais, que determinam o desenvolvimento do SUS22.

“[...] Na construção das atividades pedagógicas gerou maior empenho e dedicação que me subsidiou frente ao desafio das metodologias ativas no espaço cristalizado do trabalho e do serviço [...] e rico de nuances e experiências populares." (T5)

Como eixo integrador do ensino/pesquisa/extensão na produção do cuidado em USFs, a EPS possibilitou que a educação fosse vista como um dispositivo que liberta, pois possibilita fonte de conhecimento para maior autonomia dos usuários no cuidado de si, mas ressalta-se haver a necessidade de espaços de trocas existenciais férteis. Bem como, considerar a subjetividade de cada usuário significa perceber as diferenças, lidar com as singularidades, reconhecer suas expressões ${ }^{23}$.

"[...] todos querem trabalhar na interdisciplinaridade. Na disciplina que atuo procuro atuar no tripé ensino/pesquisa/extensão, tento fazer uma articulação na extensão. 
Como docente só reforça que queremos mudar, fortalecer a experiência [...], sempre fui contra as caixinhas, vejo o aluno querendo fazer alguma coisa com a saúde mental, sem saber o que é saúde mental." (T4)

Repensar a prática e considerar o saber do usuário permitiu, aos futuros profissionais, perceberem e valorizarem esses atores, em suas necessidades de saúde e demandas, e desmistificarem a relação saber/poder, histórica das profissões da área de saúde, que desconsideram a fragilidade do mesmo, não apenas no atendimento às suas necessidades, mas, sobretudo, no direito de conhecimento que tem sobre o seu corpo e seu agravo ${ }^{23}$.

A maioria das vivências no PET-Saúde ocorreu em espaços de produção social, onde se buscou identificar os equipamentos sociais, no território da USF, que cuidavam de crianças com problemas advindos da atenção à saúde, da gestão do cuidado e das condições socioeconômica das famílias.

Nos domicílios e na USF, foi priorizado, como problema, o desmame precoce de puérperas, e, posteriormente, agendado um encontro com mães/ESFs/UESC. A partir de então, foram construídas oficinas sobre aleitamento materno, para gestantes, e, como desdobramentos, visitas aos recém-nascidos, ao banco de leite e às puérperas, e a formação de grupos de apoio ao aleitamento materno.

$\mathrm{Na}$ creche-escola, foram priorizados problemas do estado de saúde como: dermatites, precariedade na higiene e parasitoses, e implementada uma ação intersetorial para resolvê-los. Foram desenvolvidas, em articulação com a ESF, creche, discentes, tutores e mães: a produção de pasta d'água caseira, receitas caseiras de combate à escabiose e pediculose, e a construção de cartilha sobre dermatites e hábitos higiênicos, em uma profusão de trocas de saberes. Realizou-se, ainda, feira de saúde da criança, com ações de higiene bucal, jogo da velha sobre parasitoses, e produção de DVD.

Esse processo deu-se em etapas, a partir da cogestão de coletivos que iam se implicando e afetando na redescoberta da importância de novas formas de fazer no cotidiano de trabalho da equipe saúde da família:

"[...] Falando do aleitamento, o banco de leite não era lembrado e foi feito a visita no banco e feito sempre lembrado pelas ESFs [...]." (T4)

Vivenciar outros espaços que não as unidades de saúde permitiu, aos petianos, exercitarem a EPS como ação pedagógica, compreenderem a importância da articulação intersetorial em outros territórios produtores de saúde e da reorganização dos processos de trabalho de vigilância das enteroparasitoses em crianças (sete a 14 anos), e das doenças endêmicas.

\section{Mudanças geradas pelo PET-Saúde na produção do cuidado em Saúde}

A reorganização da atenção à saúde no Brasil exige mudanças na estrutura dos serviços, nos processos formativos dos profissionais, na gestão do trabalho e do cuidado, capaz de imprimir diferentes modos de operar o trabalho em saúde.

Pensar mudanças de práticas nos leva a refletir acerca da modelagem que caracteriza o atual perfil dos profissionais de saúde, e que perpassa por uma formação enraizada em uma estrutura que, ainda, valoriza a transmissão passiva do conhecimento centrado no modelo flexeneriano, voltado para o corpo biológico, o uso de tecnologias duras com foco em máquinas e equipamentos e de leves-duras, em detrimento das leves, que priorizam as relações no trabalho em saúde ${ }^{8}$.

Esse modo de operar o cuidado tem nos levado a apostar em um novo desenho do processo de ensino-aprendizagem, mais próximo da realidade social em que estão localizados. Nessa nova proposta, os problemas e necessidades mais relevantes da população são identificados em uma tentativa: de estimular a inserção precoce do discente no cotidiano dos serviços; de fortalecer a articulação entre teoria e prática, e de incentivar uma formação global sólida com base na integração ensino-serviço-comunidade, contribuindo com a produção do cuidado integral e de qualidade.

A análise dos indicadores de morbimortalidade dos idosos acamados e das crianças, bem como a identificação de processos de descuidado muito inquietou e instigou a equipe e usuários, mobilizandoos para a implementação de estratégias e elaboração de operações para o seu enfrentamento. 
Assim, a visita domiciliar aos idosos acamados e às crianças foi considerada prioridade, pois, por meio dela, se buscaram outras formas de atender as necessidades e interesses dos usuários, trabalhadores e instituições de saúde, com a criação de projetos terapêuticos singulares que autonomizassem as pessoas em seu modo de conduzir suas vidas.

A discussão realizada sobre o significado e importância das visitas domiciliares possibilitou o envolvimento da equipe e sua valorização. Identificar crianças e idosos acamados em situação de risco ampliou o olhar da equipe para fatos mais visíveis, permitindo a inclusão dos determinantes sociais na construção dos projetos terapêuticos ${ }^{19}$. Frente às fragilidades e inquietações da equipe acerca do que fazer, foram realizadas qualificações de cuidadores de idosos, mães e agentes comunitários, e a construção de protocolos para visita domiciliar com implicação dos sujeitos envolvidos no processo de cuidar.

Na produção do cuidado no atendimento domiciliar, estão presentes as diversas dimensões implícitas e explícitas deste ato vivo, que se expressam: pelo cuidar de si, o cuidar de si junto com o outro, o ser cuidado pelo outro, o sentir o sistema pessoal em processar o cuidado do corpo por si próprio, o ser/estar no sistema de relações múltiplas de cuidado e o cuidado com o ambiente.

\section{Considerações finais}

As vivências no PET-Saúde permitiram aproximações entre serviços/ensino/população, diminuindo a fragmentação de conteúdos que capturam a formação de profissionais de saúde para atuar e fortalecer o foco do cuidado em indivíduos, famílias e comunidades nos diversos espaços de sua produção.

Dentre os dispositivos que contribuíram para a formação profissional e novos modos de cuidar, observaram-se: a inserção precoce dos alunos nos cenários de prática do SUS; compartilhamento de saberes e práticas; trabalho em equipe, a EPS; processos comunicacionais mais horizontais, e a implicação dos sujeitos com seu fazer. Esses dispositivos têm permitido algumas mudanças na micropolítica do processo de trabalho, que poderão ser institucionalizadas pelos órgãos de formação e dos serviços de saúde.

As práticas cuidadoras das equipes nas áreas de abrangência das USFs configuraram como o trabalho em saúde tem sido desenvolvido, e indicaram uma forte implicação desses profissionais com a lógica de funcionamento institucional que revela uma tendência de atuação na dimensão cuidadora do trabalho em saúde centrada no compartilhamento de saberes disciplinares e tecnologias relacionais, cujo foco de intervenção foi s elaboração de planos terapêuticos segundo os protocolos construídos de forma conjunta entre os trabalhadores da equipe, tutores, preceptores, alunos e a comunidade, nas reuniões da equipe.

Apesar de o esforço do PET-Saúde e de algumas equipes para realizar outros modos de produzir, a existência de dificuldades constantes, como a falta de infraestrutura das unidades e de insumos necessários para atender as necessidades e problemas de saúde dos usuários e trabalhadores, vem colocando limites na capacidade inventiva dos trabalhadores.

Na relação profissional-usuário-estudante, é visível a hegemonia do saber técnico sobre o saber do senso comum, carecendo uma maior horizontalização das relações de poder e utilização da EPS como dispositivo potente capaz de modificação de processos de trabalho e do modelo hegemônico de cuidar.

Os serviços de saúde constituem espaços de produção social e de aprendizado, podendo se constituir ou não em espaços produtores de saúde e de qualidade de vida. Nesse contexto, as relações intersubjetivas se revelaram como ferramentas de potência para as equipes, os tutores, os preceptores e os discentes, oportunizando a vivência de processos de aprendizagem significativa, que irão contribuir com a formação de profissionais éticos e políticos comprometidos com a defesa da vida e com a qualidade dos serviços prestados à população.

O Pet-Saúde vivenciou e contribuiu com a reestruturação produtiva em curso de mudança dos desenhos organizativos de saúde, quando potencializa o trabalho vivo em ato no atendimento às necessidades dos usuários na atenção básica; ao integrar o serviço/ensino/comunidade; ao 
proporcionar uma relação dialógica entre sujeitos do cuidar; ao respeitar singularidades, crenças e linguagem, estimulando a construção de novos processos cuidadores. Em verdade, apesar de ocorrerem importantes mudanças no modo de produção do cuidado, persistem, ainda, fortes características do modelo médico hegemônico voltado para regras próprias de mercado.

No que pese o reconhecimento, pelos relatos dos participantes nos PET-Saúde, de processos de construção próprios nos serviços de saúde, percebeu-se pouca implicação da macrogestão e instituições formadoras para promoverem mudanças mais duradouras. Potencializaram-se trabalhadores e estudantes do PET para a produção do cuidado em saúde em espaços da microgestão como espaços de aprendizado.

\section{Colaboradores}

Todos os autores participaram juntos em todas as etapas de produção do manuscrito.

\section{Referências}

1. Albuquerque VS, Batista RS, Tanji S, Moço ET-SM. Currículos disciplinares na área de saúde: ensaio sobre saber e poder. Interface (Botucatu). 2009;13(31):261-72. http://dx.doi.org/10.1590/S1414-32832009000400003

2. Feuerwerker LCM. Reflexões sobre as experiências de mudança na formação de profissionais de saúde. Olho Mágico. 2003;10(3):21-6.

3. Ceccim RB, Ferla AA. Educação e saúde: ensino e cidadania como travessia de fronteiras. Trab Educ Saúde. 2008;6(3):443-56. http://dx.doi.org/10.1590/S1981-77462008000300003

4. Cecim RB, Feuerwerker LCM. O quadrilátero da formação para a área de saúde: ensino, gestão, atenção e controle social. Physis. 2004;14(1):41-65. http://dx.doi.org/10.1590/S0103-73312004000100004

5. Ministério da Saúde. Secretaria de Gestão do Trabalho e da Educação na Saúde. Departamento de Gestão da Educação na Saúde. Política de educação e desenvolvimento para o SUS: caminhos para a educação permanente em saúde: pólos de educação permanente em Saúde. Brasília, DF: Ministério da Saúde; 2004. (Série C. Projetos, Programas e Relatórios).

6. Ministério da Saúde, Ministério da Educação. Pró-Saúde: programa nacional de reorientação da formação profissional em saúde. Brasília, DF: Ministério da Saúde; 2007.

7. Ministério da Saúde. Secretaria de Gestão do Trabalho e da Educação na Saúde. Diretoria de Gestão da Educação na Saúde. EducarSUS: notas sobre o desempenho do departamento de Gestão da Educação na Saúde, período de janeiro de 2004 a junho de 2005. Brasília, DF: Ministério da Saúde; 2004.

8. Merhy EE. Saúde: a cartografia do trabalho vivo. 2a ed. São Paulo: Hucitec; 2005.

9. Minayo MCS. Estrutura e sujeito, determinismo e protagonismo histórico: uma reflexão sobre a práxis da saúde coletiva. Ciênc Saúde Colet. 2001;6(1):7-19. http://dx.doi.org/10.1590/S1413-81232001000100002

10. Coelho Ferreira VS. Intersectorialidad en salud: un estudio de caso. In: Hartz, ZMA, Vieira-da-Silva, LM, organizadoras. Evaluación en salud: de los modelos teóricos a la práctica em la evaluación de programas y sistemas de Salud. Buenos Aires: Lugar Editorial; 2009. p. 101-48.

11. 11. Franco TB. Produção do cuidado e produção pedagógica: integração de cenários do sistema de saúde no Brasil. Interface (Botucatu). 2007;11(23):427-38. http://dx.doi.org/10.1590/S1414-32832007000300003 
12. Donabedian A. La capacidade de la atención médica: definición e métodos de evaluación. 4a ed. México: La prensa Médica Mexicana; 1984.

13. Baremblitt G. Compêndio de análise institucional. 5a ed. Belo Horizonte: Instituto Félix Guattari; 2002.

14. Minayo MCS. O desafio do conhecimento: pesquisa qualitativa em saúde. 12a ed. São Paulo: Hucitec; 2010.

15. Braid LMC, Machado MFAS, Aranha AC. Estado da arte das pesquisas sobre currículo em cursos de formação de profissionais da área da saúde: um levantamento a partir de artigos publicados entre 2005 e 2011. Interface (Botucatu). 2012;16(42):679-92. http://dx.doi.org/10.1590/S1414-32832012000300008

16. Nietzsche F. Vontade de potência. Petrópolis: Vozes; 2011. (Coleção Textos filosóficos)

17. Deleuze G, Guattari F. Mil platôs: capitalismo e esquizofrenia. Rio de Janeiro: Editora 34; 1995.

18. Lourau R. Implicação e sobreimplicação In: Altoé S, organizadora. René Lourau: analista Institucional em tempo integral. São Paulo: Hucitec; 2004. p. 186-98.

19. Guatarri F, Rolnik S. Micropolítica: cartografias do desejo. 7a ed. Petrópolis: Vozes; 2005.

20. Lacerda MR, Giacomozzi CM, Oliniski SR, Truppel TC. Atenção à saúde no domicílio: modalidades que fundamentam sua prática. Saúde Soc. 2006;15(2):88-95. http://dx.doi.org/10.1590/S0104-12902006000200009

21. Deleuze G. Cursos sobre Spinoza. 2a ed. Fortaleza: EdUECE; 2009.

22. Araújo MCF. Estágio supervisionado no currículo de Enfermagem. Salvador [tese]. Salvador: Universidade Federal da Bahia; 2011.

23. Coelho Ferreira VS. Micropolítica do processo de trabalho do agente comunitário de saúde (ACS): território de produção de cuidado e subjetividade Rio de Janeiro [tese]. Rio de Janeiro: Universidade Federal do Rio de Janeiro; 2008. 
Ferreira VSC, Andrade CS, Fontes AMDV, Araújo MCF, Anjos SDS. Maneras de cuidar y educar de acuerdo con el Programa de Educación en el Trabajo para la Salud. Interface (Botucatu). 2015;19 Supl 1:857-68.

Históricamente la formación de los profesionales de la salud se ha centrado en contenidos de salud fragmentados que privilegian el determinismo biológico y la enfermedad como consumo. La adopción de las políticas de reorientación de la formación en las instituciones de enseñanza fomenta nuevas formas de enseñar y cuidar. Fueron analizados los mecanismos de coordinación entre los actores involucrados y los dispositivos que contribuyeron para la reconversión profesional y el cuidado de la producción. Optamos por el estudio cualitativo evaluativo. Los instrumentos de recolección fueron: grupos focales, observación directa y análisis de documentos y el análisis de contenido . Los resultados indican una aproximación entre los servicios/educación/población, la disminución de la fragmentación de los contenidos, el fortalecimiento de la educación sanitaria, los cambios en el trabajo de las micropolíticas, intercambio de conocimientos y la práctica, implicación de los sujetos con lo que hacen.

Palabras clave: Programa de Educación en el Trabajo para la Salud (PET-Salud). Educación permanente en salud. Formación en salud. Cuidado en salud. 